\title{
Investigation of Some Phytochemical Compounds Found in Anchusa strigosa L. Grown Naturally in Iraq
}

\author{
Suroor A. Ghalib*,1 and Enass J. Kadhim*
}

"Department of Pharmacognosy and Medicinal Plants, College of Pharmacy, University of Baghdad,Baghdad,Iraq

\section{Abstract}

Anchusa strigosa L.: perennial herb, with hairs especially on the leaves., flowers generally regular. Commonly named (Lisan Althour) in Iraq, from Boraginaceae family. The plant contain phenolic acids, flavonoids, alkaloids,sterols and terpenoids. Whole plant part deffated n-hexane for 24 hours. The deffated plant material extracted using absolute methanol by Soxhlet apparatus until complete exhaustion, the extract fractionated by solvents of different polarity: petroleum ether- chloroform - ethylacetate- and n-butanol respectively. The n-butanol fraction hydrolyzed with $5 \% \mathrm{HCl}$ for 5 hours by reflex to break down the glycosidic linkage. Rosmarinic acid, caffeic acid, genistein and silybin were isolated from ethyl acetate fraction by preparative thin layer chromatography which identified by high performance liquid chromatography HPLC, Fourier transforms infrared (FTIR) spectra, thin layer chromatographyTLC and melting point. Since the plant contain alkaloids so acid-base extraction was performed for crude extract resulting from maceration of the plant parts in methanol (cold method) to obtain the alkaloid that isolated by preparative thin layer chromatography and then identified by Fourier transforms infrared (FTIR) spectra and thin layer chromatography(TLC).

The aim of this research was to carry out a phytochemical study of this plant since no previous phytochemical investigation work had been done on this species in Iraq

Keywords: Anchusa strigosa ,Rosmarinic acid, Sterol ,Acid -base extraction.

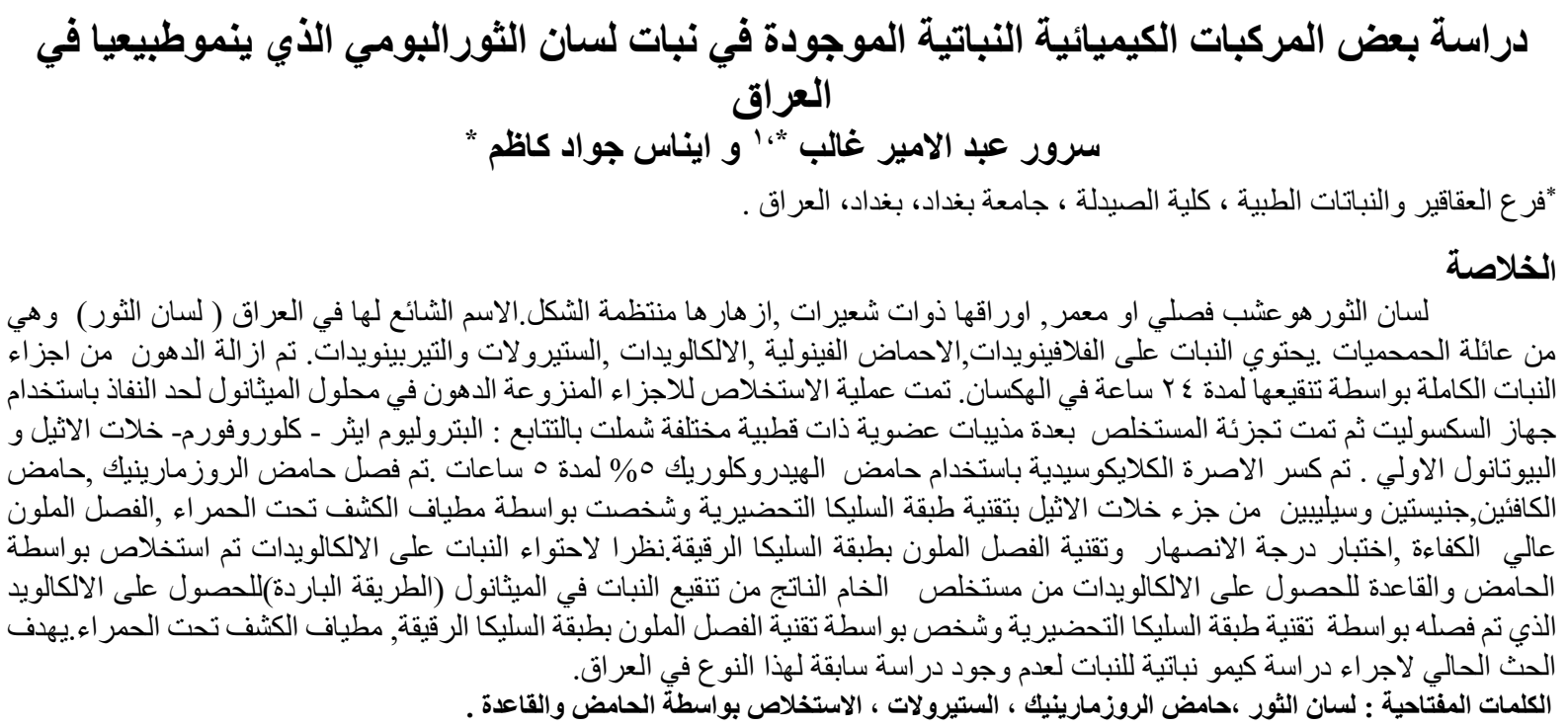

\section{Introduction}

Hardy annual biennial or perennial herb (1), usually with hairs on the leaves, the flowers generally regular ${ }^{(2)}$. Commonly named (Lisan Althour) in Iraq, from Boraginaceae family ${ }^{(3)}$ that distributed in the temperate, usually in Mediterranean and tropical regions; in Iraq is common on the road sided in middle and southern regions ${ }^{(1)}$.

The plants of Boraginaceae family contain naphthaquinones, flavonoids, terpenoids and phenols However, these plants also have hepatotoxic pyrrolizidine alkaloids. ${ }^{(4)}$ Plants of the Boraginaceae family are traditionally used in the treatment of fever, asthma, kidney stones, wound healing, treatment of arthritis, sprains or dislocation of the joints and bone fractures (5) Flowers of Anchusa italica Retz. and Anchusa strigosaL. used as tea: tonic to invalids and children; lower pulsation. It is a substitute of Anchusa offisinalis used as a diaphortic and diuretic ${ }^{(6)}$. In Turkey some Anchusa species used traditionally as wound healing and diuretic agent and others as demulcent, expectorant, analgesic, sedative ${ }^{(7)}$ In Jordon and Palestine the root decoction is used as diuretic, for abdominal pain and for treatment of gastric ulcer, while the leaves juice is applied externally for skin disease, arithritis and wounds ${ }^{(8,9)}$.

${ }^{1}$ Corresponding author E-mail: suroor.amir@yahoo.com

Received: $29 / 8 / 2020$

Accepted: 21/ 11/2020

Iraqi Journal of Pharmaceutical Science 
Different species of Anchusa extract have many pharmacological activities ; methanolic extract of Anchusa officinalis L has great antioxidant activity as free radical scavenging due to phenolic and flavonoids content, ${ }^{(10)}$ While this activity is great for aqueous extract of Anchusa strigosa (11) antihyperglycemic activity of $A$. strigosa in diabetic rats showed a significant decrease in the fasting blood glucose and an increase in the serum insulin levels after administration that possibly was either by increasing the pancreatic secretion of insulin from existing $\beta$-cells or by release from the bound form (12) The uses of Anchusa strigosa extract has neuroprotective activity against amyloid toxicity ; reducing levels of amyloid secretion from cells and reduced $\gamma$-secretase activity ${ }^{(13)}$. The volatile oil of Anchusa strigosa L. has strong antibacterial activity against both Gram positive and Gram negative bacteria in a high concentration ${ }^{(14)}$, the antioxidant activity due to phenolic and flavonoids content of anchusa italica may be beneficial in ischemic patients ${ }^{(15)}$ on the other hand A. strigosa aqueous and methanol extracts has anti arithritis activity ${ }^{(16)}$ also finding that the petroleum ether fraction of Anchusa strigosa has effective anti-ulcer profile ${ }^{(17)}$.

Anchusa strigosa contain many secondary metabolites including pyrolizidine alkaloids with high concentration in the leaves followed by the flowers and finally by the roots such as retrorsine, trachelanthamidine, supinidine, platynecine and Heliotridine ${ }^{(9,18)}$,flavonoids and phenolic acid content of this plant including Catechins, Quercitin,rosmarinic acid caffeic acid and others $(19,20)$,this plant also contains steroids and terpenoids as tormentic acid. ${ }^{(5)}$

This study aim is to carry out a phytochemical study of Iraqi Anchusa strigosa for isolation of some phenolic acid,flavonoids and alkaloid.

\section{Experimental Section Plant material}

The whole plant of Anchusa strigosa L. of family (Boraginaceae) was collected from Khalow Bazian near Kirkuk during April at the flowering stage and the plant was authenticated by Dr. Abdul Hussein Alkhiat, specialist in plant taxonomy in College of Sciences/ University of Erbil.

\section{Extraction}

Anchusa strigosa whole plant parts were cleaned, dried at room temperature for 7 days, pulverized by mechanical milled and then weighed. About (500gm) of powdered plant defatted by maceration in pure $n$-hexane for 24 hours, filtered through a wattman paper, then filled in the thimble and extracted with sufficient amount of absolute methanol by a Soxhlet extractor until complete exhaustion. This extract was concentrated using rotary evaporator. After complete evaporation of the solvent, dry extract was weighted and dissolved in $350 \mathrm{ml}$ water, partitioned with $350 \mathrm{ml}$ (3times) petroleum ether, chloroform, ethylacetate and butanol. Each fraction evaporated by rotary evaporator, dry, weighted and revealed for preliminary test. The n-butanol fraction was hydrolyzed by reflex with $10 \% \mathrm{HCl}$, and then the hydrolyzed fraction was taken with ethyl acetate then dried for further investigation.

\section{Preliminary phytochemical examination of crude} methanolic extract:

To identify the phytochemicals in the methanolic extract, general phytochemical screening was performed ${ }^{(21)}$

\section{Alkaloids test by Wagner's reagent}

To 2-3 ml filtrate few drops of Wagner's reagent were added to test for the presence of alkaloids; if positive it gives brown yellow precipitate.

\section{Test for polyphenol (ferric chloride test)}

Three $\mathrm{ml}$ of methanolic extract was mixed with $(5 \mathrm{ml})$ of distilled water. To this solution 4-5 drops of $5 \%$ ferric chloride solution was added. Development of bluish black color indicates the presence of polyphenol.

\section{Test for sterols}

$\mathrm{H}_{2} \mathrm{SO}_{4}$ test: one $\mathrm{ml}$ of methanolic extract was mixed with $(1 \mathrm{ml})$ acetic acid, to which equal volume of concentrated sulfuric acid was added from the side. The development of blue, green ring at the interface indicates the presence of sterol.

\section{Test for saponins}

A bout $2 \mathrm{gm}$ of the powdered extract was boiled in $20 \mathrm{ml}$ of distilled water in a water bath and filtered, $10 \mathrm{ml}$ of the filtrate mixed with $5 \mathrm{ml}$ of distilled water in test tube and shaken vigorously. The presence of saponins indicated by a characteristic persistent froth at least $1 \mathrm{~cm}$ in height.

\section{Detection of beta-sitosterole and tormentic acid by thin layer chromatography}

Few milligrams from the petroleum ether fraction were suspended in about one $\mathrm{ml}$ of absolute methanol, applied to a readymade analytical TLC plate precoated with silica gel $\mathrm{GF}_{\mathbf{2 5 4}}$, and developed in two mobile phases: chloroform: methanol (100:10) and toluene: ethylacetate: chloroform (5:1:4) After development, the plates were allowed to dry at room temperature and the separated spots were detected by LiebermannBurchard reagent used for identification of steroidal compounds ${ }^{(22)}$.

\section{Isolation of flavonoids and phenolic acid Compounds by Preparative layer chromatography $P L C$ from the ethyl acetate fraction}

Flavonoids and phenolic compounds were isolated by preparative layer chromatography PLC from the ethyl acetate fraction of A. Strigosa Preparative silica gel $\mathrm{GF}_{254}$ plate of $20 \times 20 \mathrm{~cm}$ dimension with a layer thickness of $1 \mathrm{~cm}$. reactivated 
by heating at $120^{\circ} \mathrm{C}$ for $15-20 \mathrm{~min}$, then cooled for the application of the sample.

One mobile phase: chloroform: methanol: formic acid (75:20:5) for ethyl acetate fraction was used, placed in jar, the jar was lined with a filter paper closed tightly, and left for saturation.

Sample application was done by dissolving $1 \mathrm{~g}$ of the sample in absolute methanol and applied to the baseline of preparative PLC plate using capillary tubes, the marked bands were scrapped out of the preparative plate on separated papers using a fine spatula. Each band's powder was introduced in an individual clean and dry conical flask, a sufficient quantity of absolute methanol was added, and the flasks were shaken on a warm water bath, filtered through microporous filter (seaterd) then with filter paper. The solvent was evaporated under reduced pressure using rotary evaporator.

The isolated flavonoid and phenolic compounds from ethyl acetate fraction were identified by HPLC, TLC, FTIR and melting point.

Detection of isolated compounds by thin layer chromatography (TLC)

Analytical TLC was performed for each separated compound by using: chloroform: methanol: acetic acid (87.5:10:2.5) solvent system for isolated caffeic acid \&: chloroform: methanol: formic acid (75:20:5) solvent system for isolated rosmarinic acid to measure the $R_{\mathbf{f}}$ value (retardation factor) for that compound and comparing it with standard material.

\section{Detection of isolated compounds by HPLC analysis} The samples and standard that detected by HPLC include: ethyl acetate, n-butanol fraction before hydrolysis, four isolated bands, rosmarinic acid std., caffeic acid std., apigenine std., kaempferol std., genistein std., silybin std.

Each sample was dissolved in 200 microliter methanol prior to inject in HPLC system.

The separation was achieved on $\mathrm{C} 18$ column (Knuaer, Germany) (250 -4.6 mm i.d., $5 \mu$ m particle size, $80 \AA$ pore size ) .

The mobile phase contains $1 \%$ aq. acetic acid solution (Solvent A) and acetonitrile (Solvent B), the flow rate was adjusted to $1 \mathrm{ml} / \mathrm{min}$, the column was thermostatically controlled at $280 \mathrm{C}$ and the injection volume was kept at $20 \mu \mathrm{l}$.

A gradient elution was performed by varying the proportion of solvent $\mathrm{B}$ to solvent $\mathrm{A}$ as shown below.

\begin{tabular}{||l|l|l|l||}
\hline \hline Time (min) & Mobile A (\%) & Mobile B (\%) & Flowrate $\mathrm{ml} / \mathrm{min}$ \\
\hline 0 & 90 & 10 & $1 \mathrm{ml} / \mathrm{min}$ \\
\hline 28 & 60 & 40 & $1 \mathrm{ml} / \mathrm{min}$ \\
\hline 39 & 40 & 60 & $1 \mathrm{ml} / \mathrm{min}$ \\
\hline 60 & 10 & 90 & $1 \mathrm{ml} / \mathrm{min}$ \\
\hline
\end{tabular}

HPLC chromatograms were detected using a photo diode array UV detector at three different wavelengths $(272,280$ and $310 \mathrm{~nm}){ }^{(23)}$

\section{Detection of isolated compounds by FTIR analysis}

The isolated compounds subjected to

FTIR analysis to identify the functional groups. The following condition and apparatus were used SHIMADZU 3800 FT-IR/ Japan in the Pharmaceutical Chemistry Department at AL Mustansiriyah University / College of Science.

Detection of isolated compounds by melting point Using melting point apparatus Stuart melting point /SMP30.

\section{Acid-base extraction of alkaloids from crude extract}

Part of the crude extract from hot method \&all extract obtained from cold method (maceration of whole plant part in absolute methanol for 24 hours) were first defatted with n-hexane and partitioned with water to remove pigment and fatty materials $(150 \mathrm{ml} * 3)$ then the aqueous part is treated with $\mathrm{NH} 4 \mathrm{OH}$ to $\mathrm{pH} 10$ to liberate free alkaloid then equal volume of chloroform is added to separator funnel partitioned and the lower organic layer was collected \& dried then acidified with $5 \% \mathrm{H}_{2} \mathrm{SO}_{4}$ to $\mathrm{pH} 2$., to this layer add $\mathrm{NH}_{4} \mathrm{OH}$ to $\mathrm{pH} 10$ and partitioned with chloroform, the chloroform layer now contains free tertiary alkaloids (24). This fraction symbolized as FK Isolation and purification of alkaloid from FK
fraction by preparative layer chromatography

The alkaloid isolated by preparative layer chromatography PLC from FK fraction of $A$. Strigosa Preparative silica gel $\mathrm{GF}_{254}$ plate of $20 \times 20$ $\mathrm{cm}$ dimension with a layer thickness of $1 \mathrm{~cm}$. reactivated by heating at $120 \mathrm{oc}$ for $15-20 \mathrm{~min}$, then cooled for the application of the sample. mobile phase: methanol: water: formic acid (25:2:73) was used, placed in jar, the jar was lined with a filter paper closed tightly, and left for saturation. Sample application was done by dissolving $1 \mathrm{~g}$ of the sample in absolute methanol and applied to the baseline of preparative PLC plate using capillary tubes, the marked bands were scrapped out of the preparative plate on separated papers using a fine spatula. Each band's powder was introduced in an individual clean and dry conical flask, a sufficient quantity of absolute methanol was added, and the flasks were shaken on a warm water bath, filtered through 
microporous filter (seaterd) then with filter paper. The solvent was evaporated under reduced pressure using rotary evaporator. The isolated alkaloid then identified by TLC, FTIR.

\section{Detection of isolated compounds by thin layer chromatography (TLC)}

Analytical TLC was performed for separated compound by using methanol: water: formic acid (25:2:73) and methanol: water: formic acid (50:50:2) as solvent system for isolated compound then sprayed with Dragendorff reagent for identification of alkaloid.

Detection of isolated compounds by FTIR Analysis

The isolated compounds subjected to FTIR analysis to identify the functional groups. The following condition and apparatus were used SHIMADZU 3800 FT-IR/ Japan in the pharmaceutical chemistry department at Mustansiriya University / college of science.

\section{Results}

Phytochemical investigation for methanolic extract of Aanchusa strigosa

Table 1 showed the major active constituents present in the crude methanolic extract of $A$.

strigose.

The present study for the Anchusa strigosa showed the presence of medicinally active qualitatively analyzed and the results are presented in Table 1.the positive results, based on the presence or absence of color change, polyphenols, alkaloid, sterols and saponins gave positive $(+)$ results.

Table1. Phytochemical analysis of Anchusa strigosa Extract

\begin{tabular}{|c|c|}
\hline $\begin{array}{c}\text { Phytochemical } \\
\text { components }\end{array}$ & Result \\
\hline Alkaloid & + \\
\hline Polyphenol & + \\
\hline Sterol & + \\
\hline Saponin & + \\
\hline
\end{tabular}

Detection of beta-sitosterole and tormentic acid by thin layer chromatography:

Depending on the color of standards spots that appear after heating and spraying TLC plate with Liebermann- Burchard reagent; beta sitosterol appeared as pink to red color while tormentic acid as purple color.

Isolation of flavonoids and phenolic acid Compounds by Preparative layer chromatography $P L C$ from the ethyl acetate fraction:

Preparative PLC was used to isolate and purify flavonoids \& phenolic compounds; using chloroform: methanol: formic acid (75:20:5) solvent system for developing the isolation. As shown in Figure (1), four bands (a,b,c,d) representing the four isolated compounds respectively $(\mathrm{R}, \mathrm{CA}, \mathrm{G}, \mathrm{S})$.

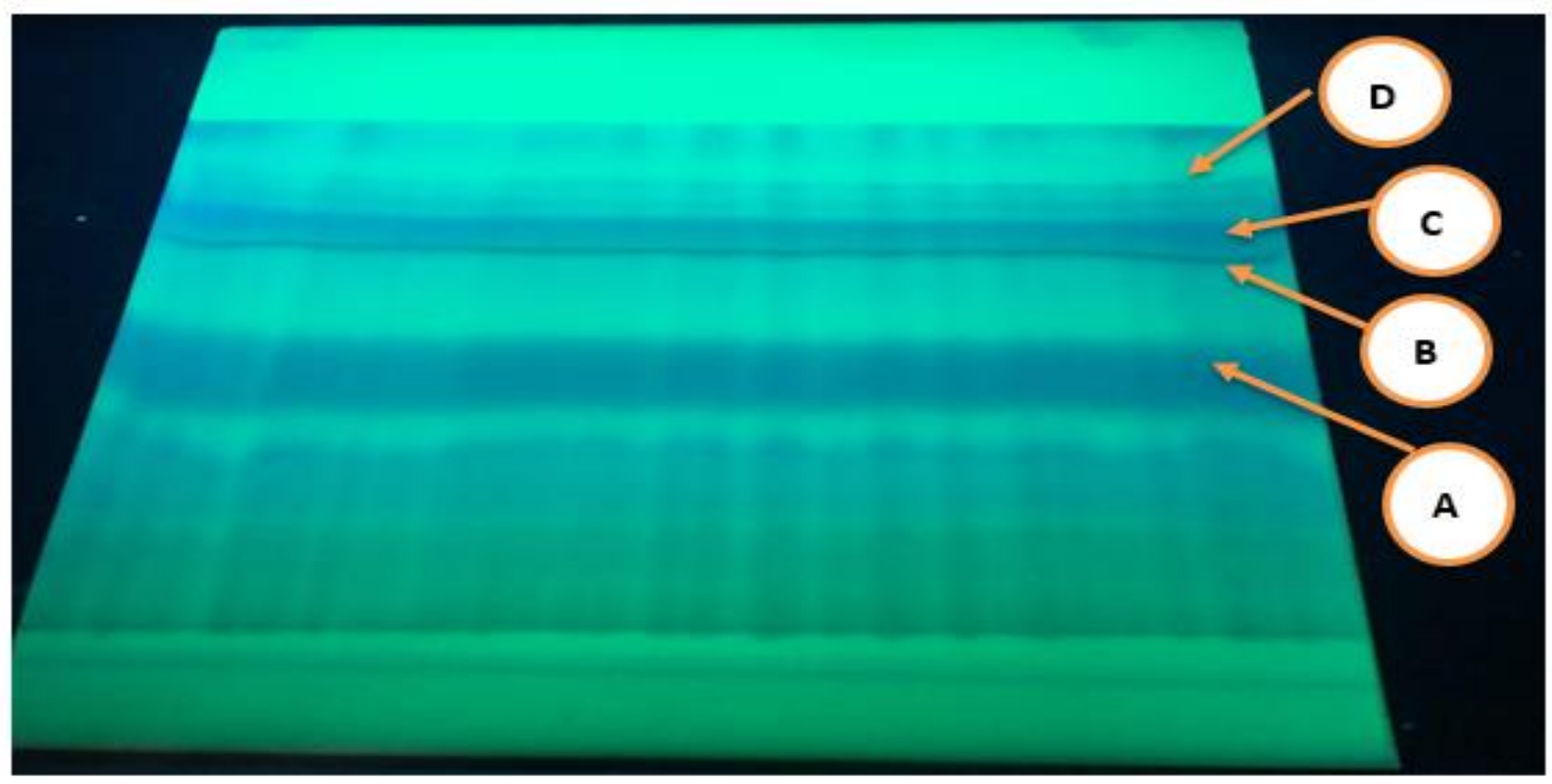

Figure 1. preparative layer chromatography for ethyl acetate fraction developed in chloroform: methanol: formic acid (75:20:5) \& detect under UV light at $254 \mathrm{~nm}$ (A: R, B:CA, C: G, D: S) 
HPLC Chromatogram for the ethyl acetate fraction

HPLC analysis were performed for the compound as shown in (Figures 4,5,6,7). ethyl acetate fraction (Figure 2, 3) and each isolated

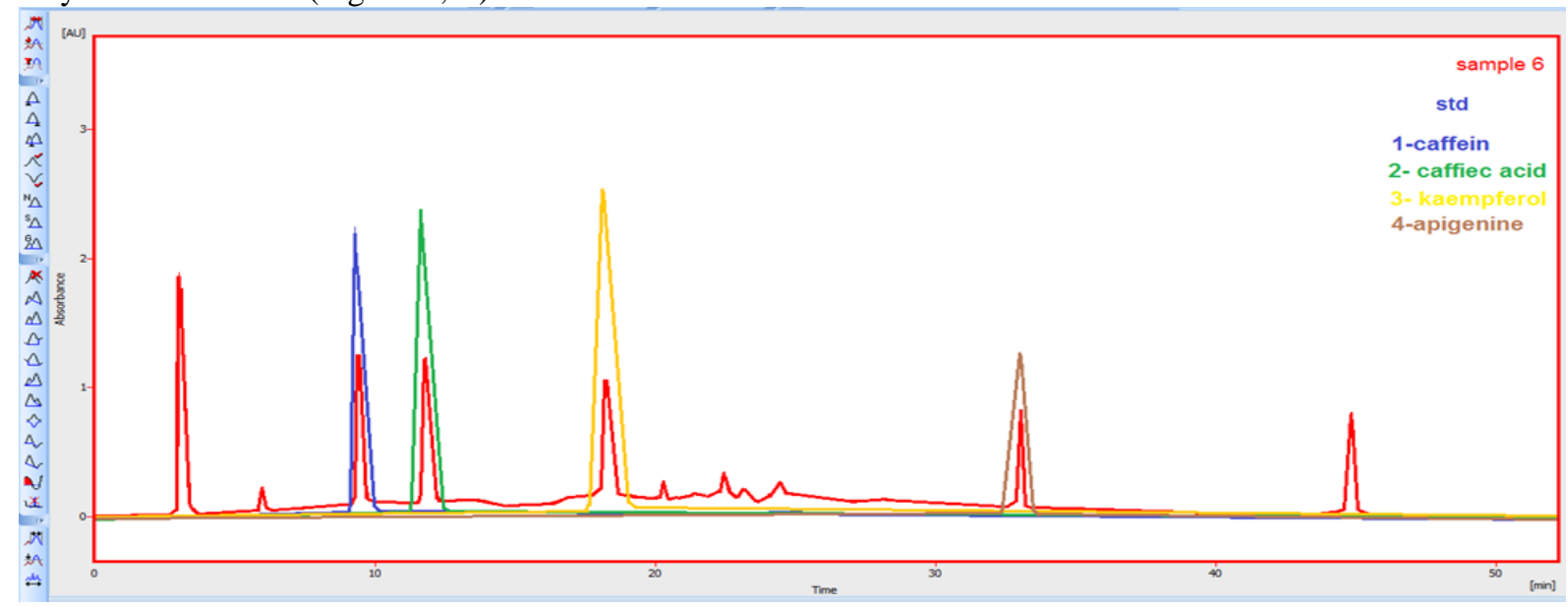

Figure 2. HPLC chromatogram of ethyl acetate fraction.

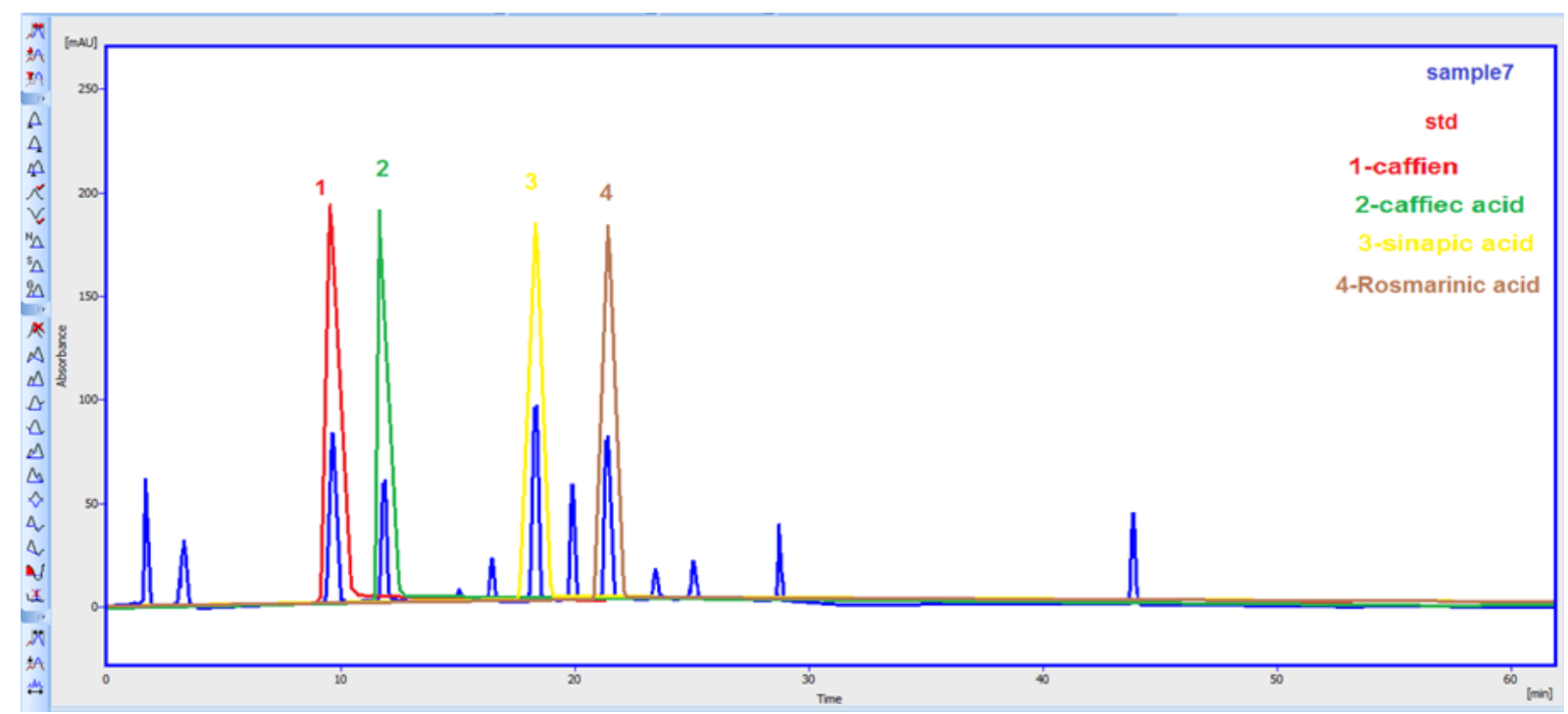

Figure 3. HPLC chromatogram of n- butanol fraction before hydrolysis

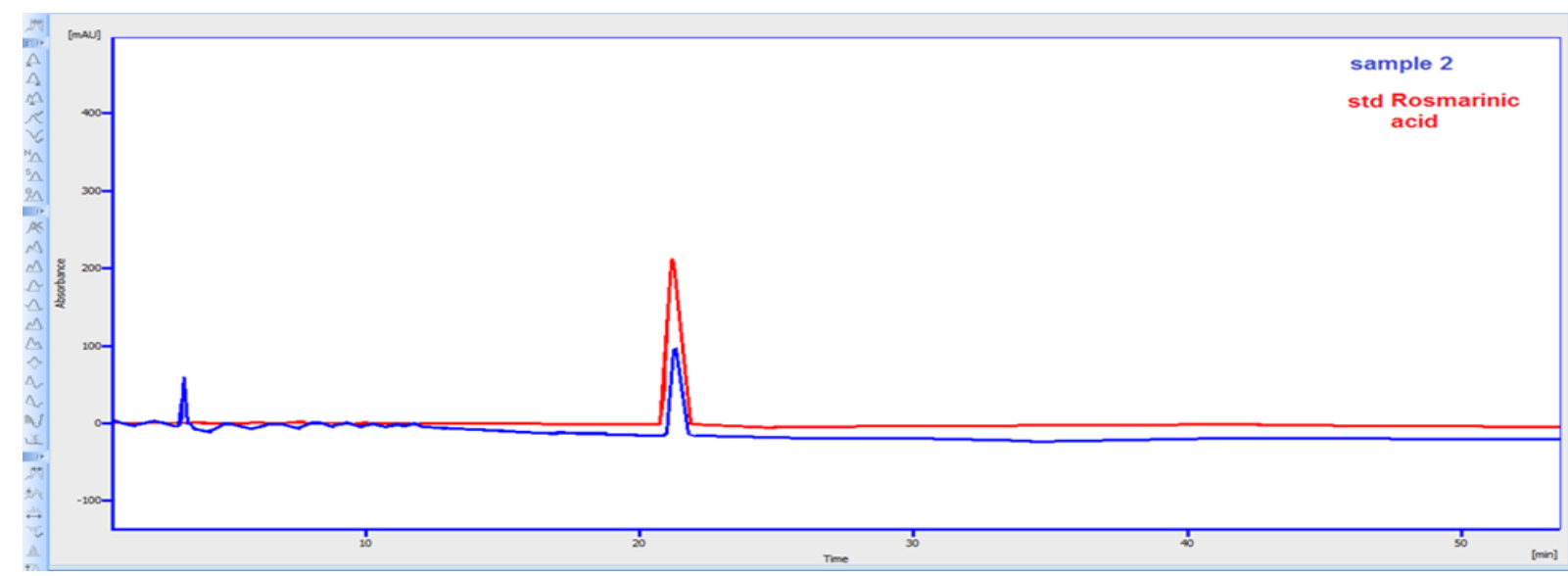

Figure 4. HPLC chromatogram of the isolated $R$ compound \& standard rosmarinic acid 


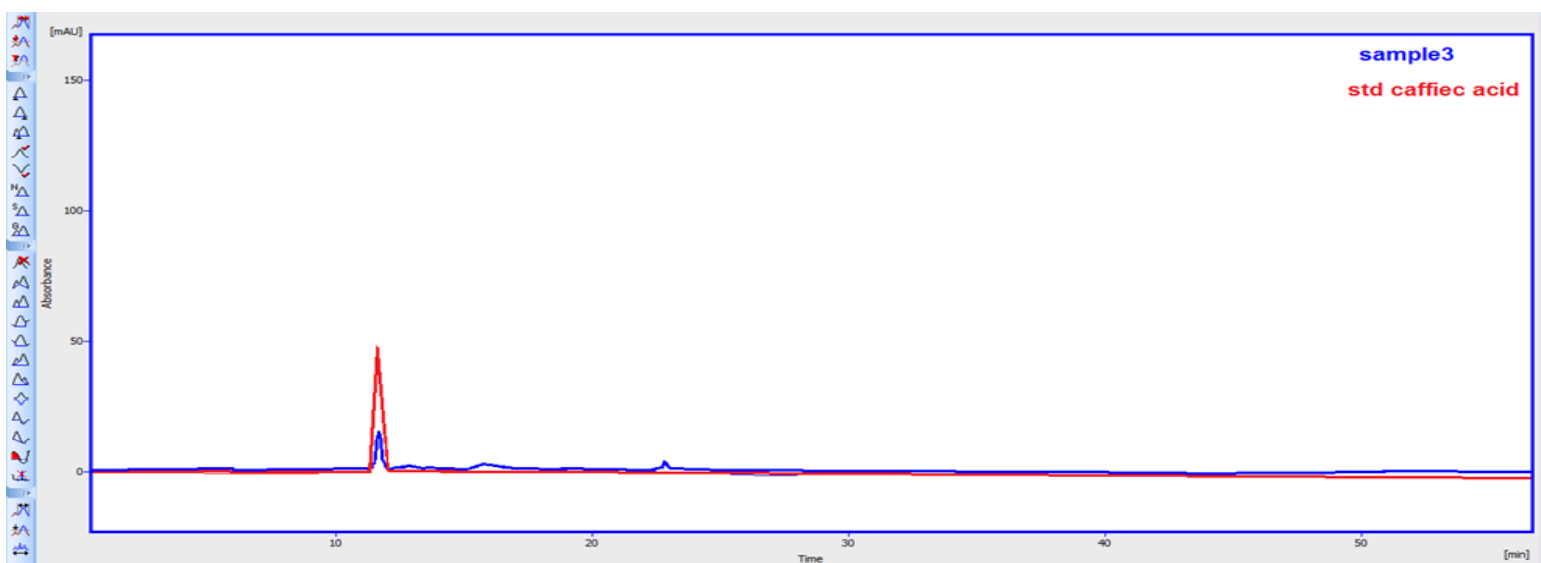

Figure 5. HPLC chromayogram of the isolated CA compound \&standard caffeic acid

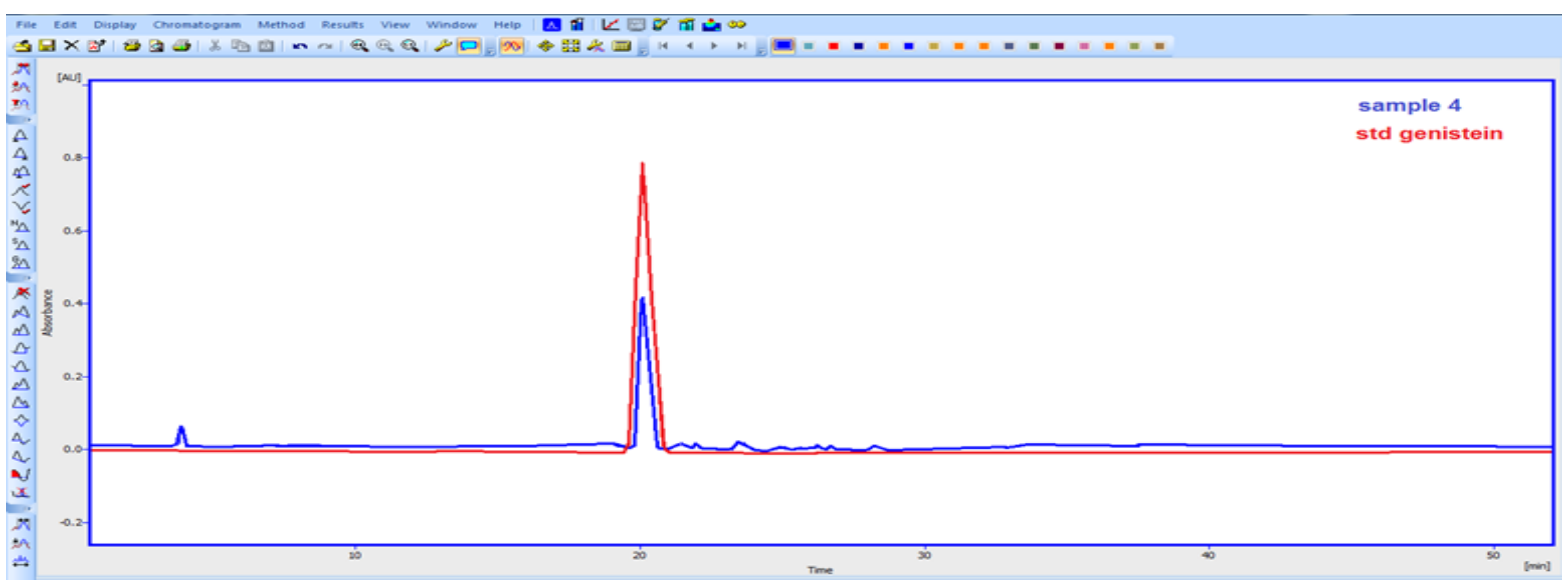

Figure 6. HPLC chromatogram of the isolated G compound \&standard genistein

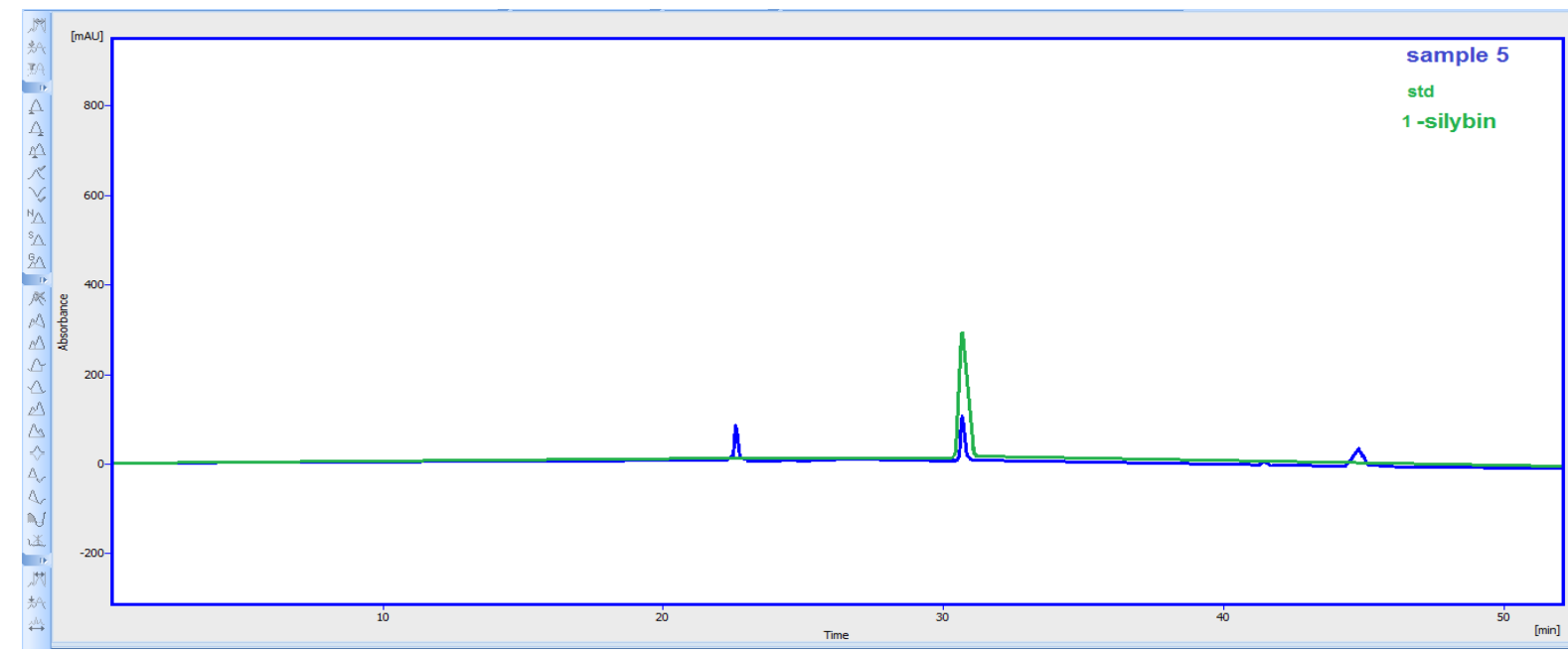

Figure 7. HPLC chromatogram of the isolated S compound \&standard silybin

\section{TLC for the isolated compounds}

This was carried out to insure the purity of the isolated compound which was isolated by scraping the isolate bands of the preparative PLC by comparing the retardation factor of isolated compound with standard. Retardation factor for isolated $\mathrm{R}$ compound compared with that of standard rosmarinic acid after developing the TLC plate in chloroform: methanol: formic acid (75:20:5); they have same $R_{f}$ value $(0.468)$, retardation factor for isolated CA compound compared with that of standard caffeic acid after developing the TLC plate in chloroform: methanol:acetic acid (87.5:10:2.5); they have approximate $\mathrm{R}_{\mathrm{f}}$ value $(0.178$ for standard \& 0.142 for isolated compound), retardation factor for isolated $\mathrm{G}$ compound was (0.837) after developing the TLC plate in chloroform: methanol: formic acid (75:20:5), retardation factor for isolated $\mathrm{S}$ compound; they have approximate $\mathrm{R}_{\mathrm{f}}$ value (0.863 for standard \& 0.818 for isolated $\mathrm{S}$ ) after developing the TLC plate in chloroform: methanol: acetic acid (87.5:10:2.5) and all the plates detected at $254 \mathrm{~nm}$ UV light. 


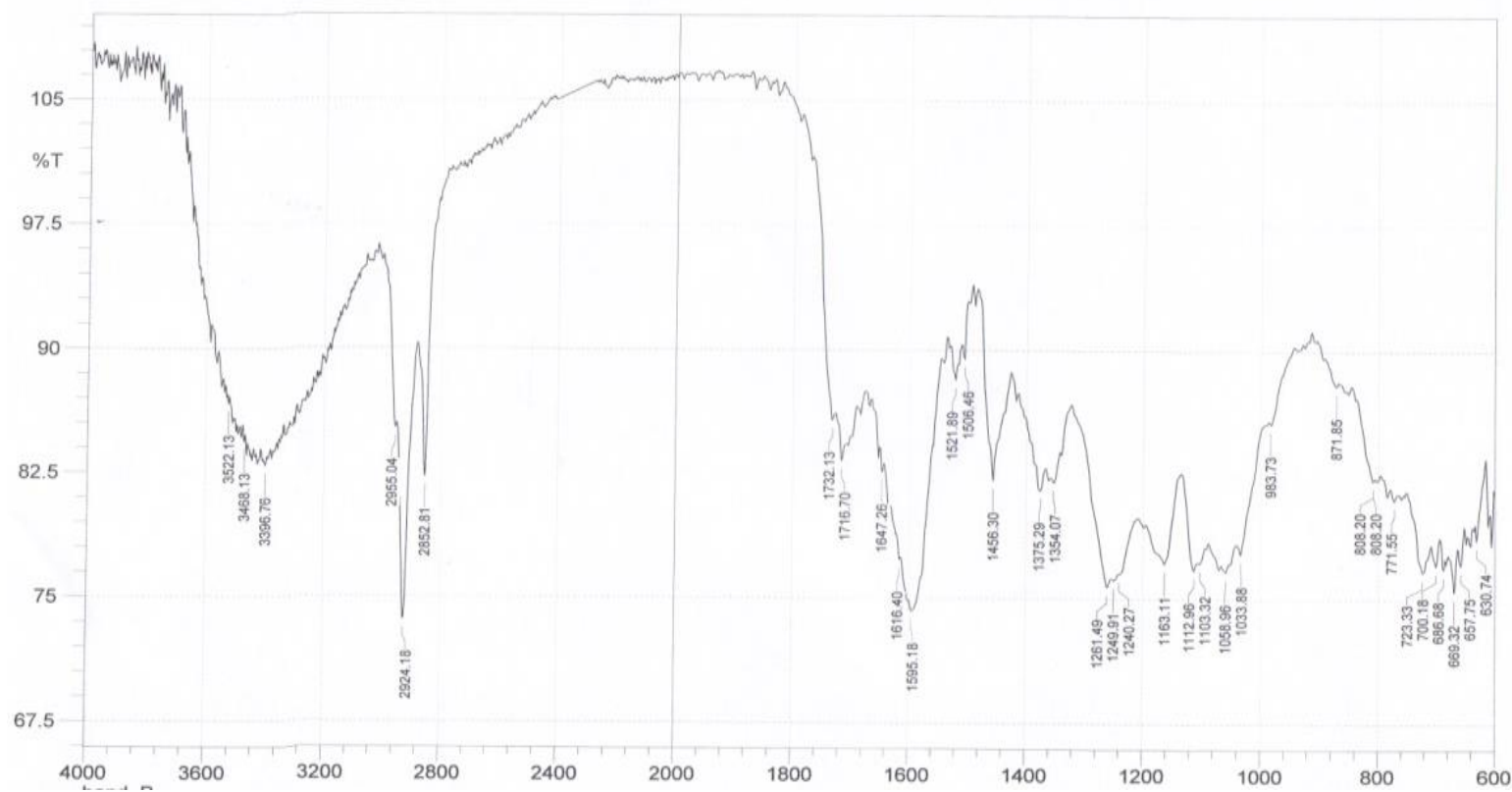

Figure 8. FTIR spectrum of isolated $R$ compound

ФSHIMADZU

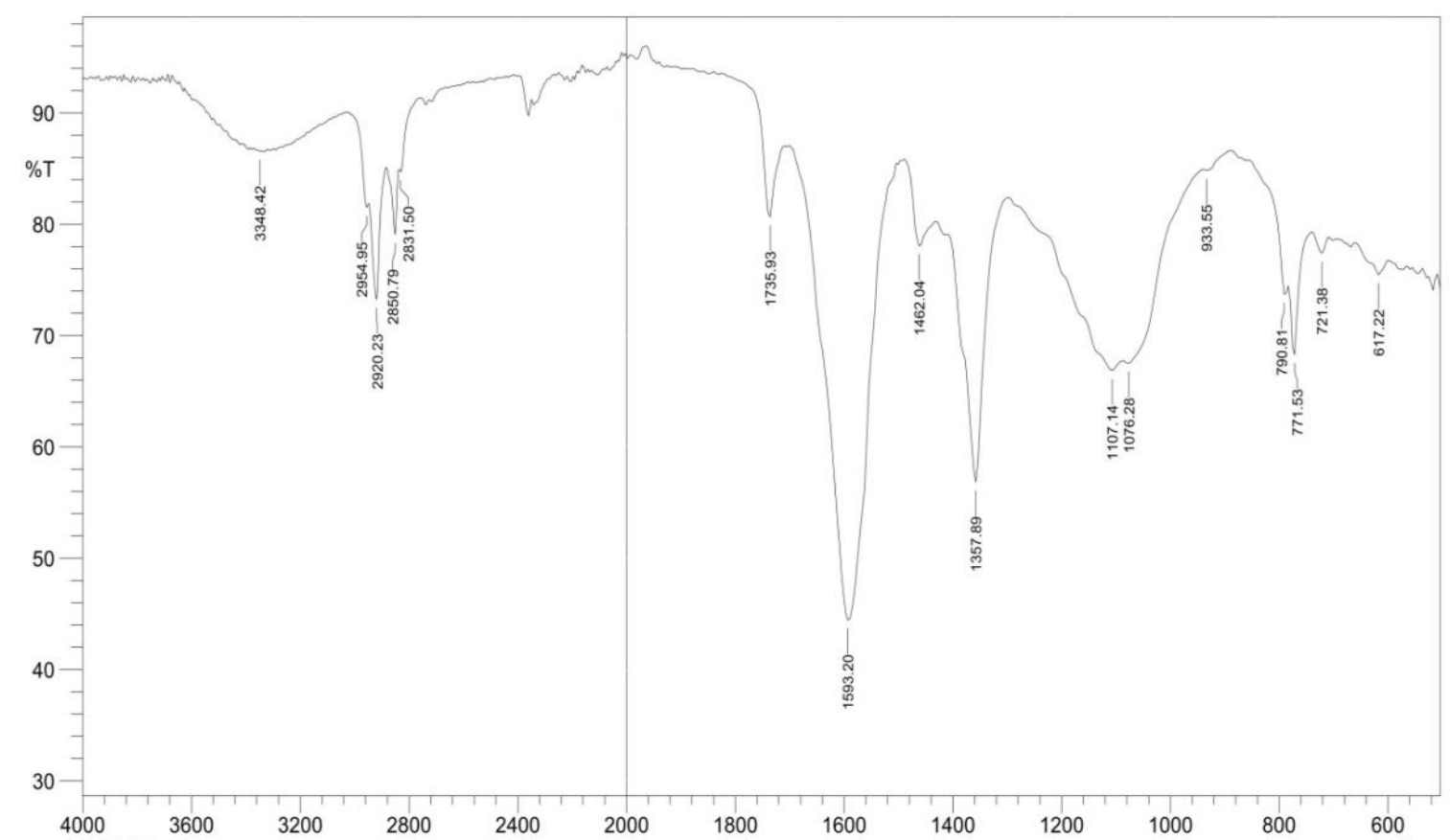

Figure 9. FTIR spectrum of isolated CA compound 


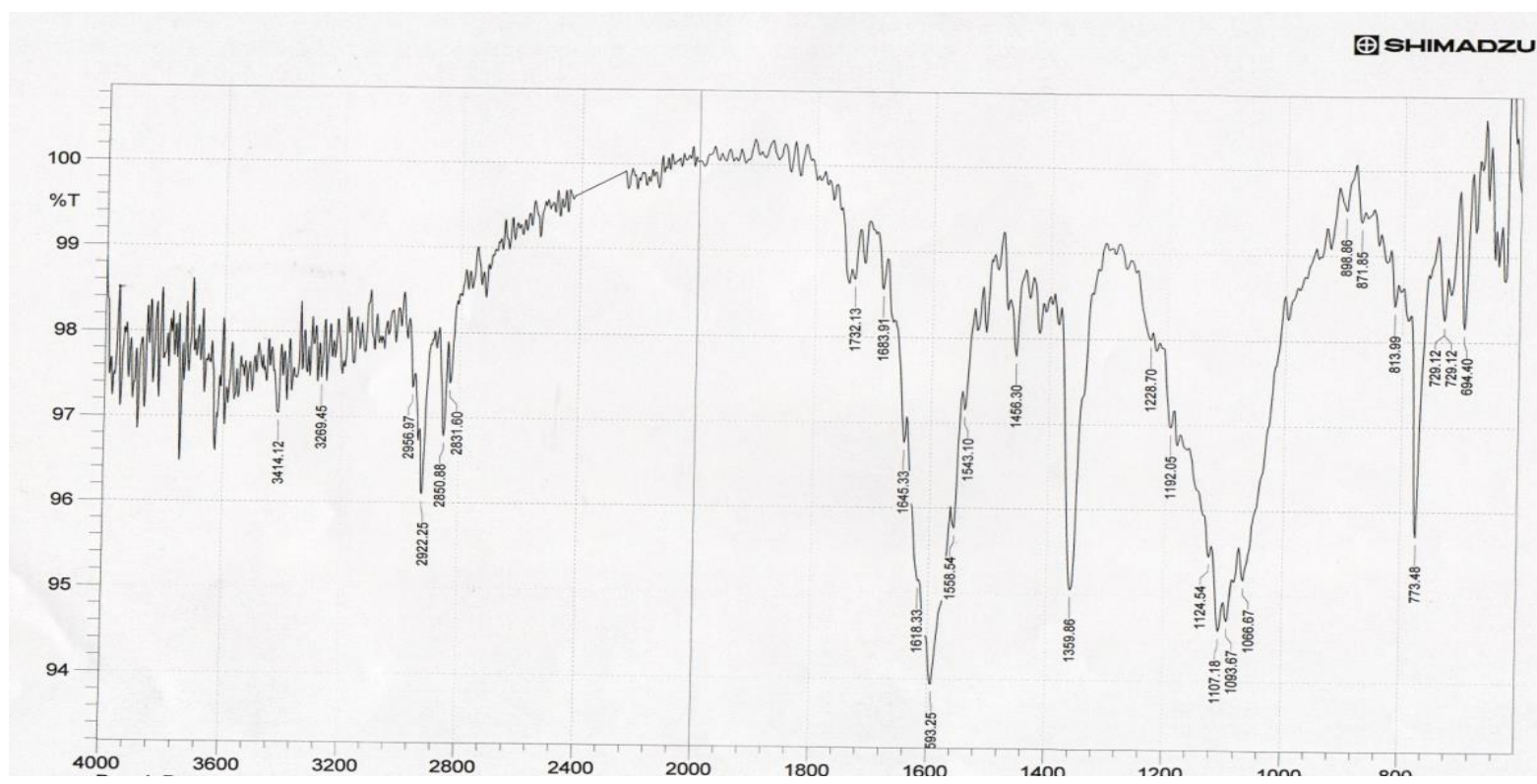

Figure 10.FTIR spectrum of isolated $G$ compound

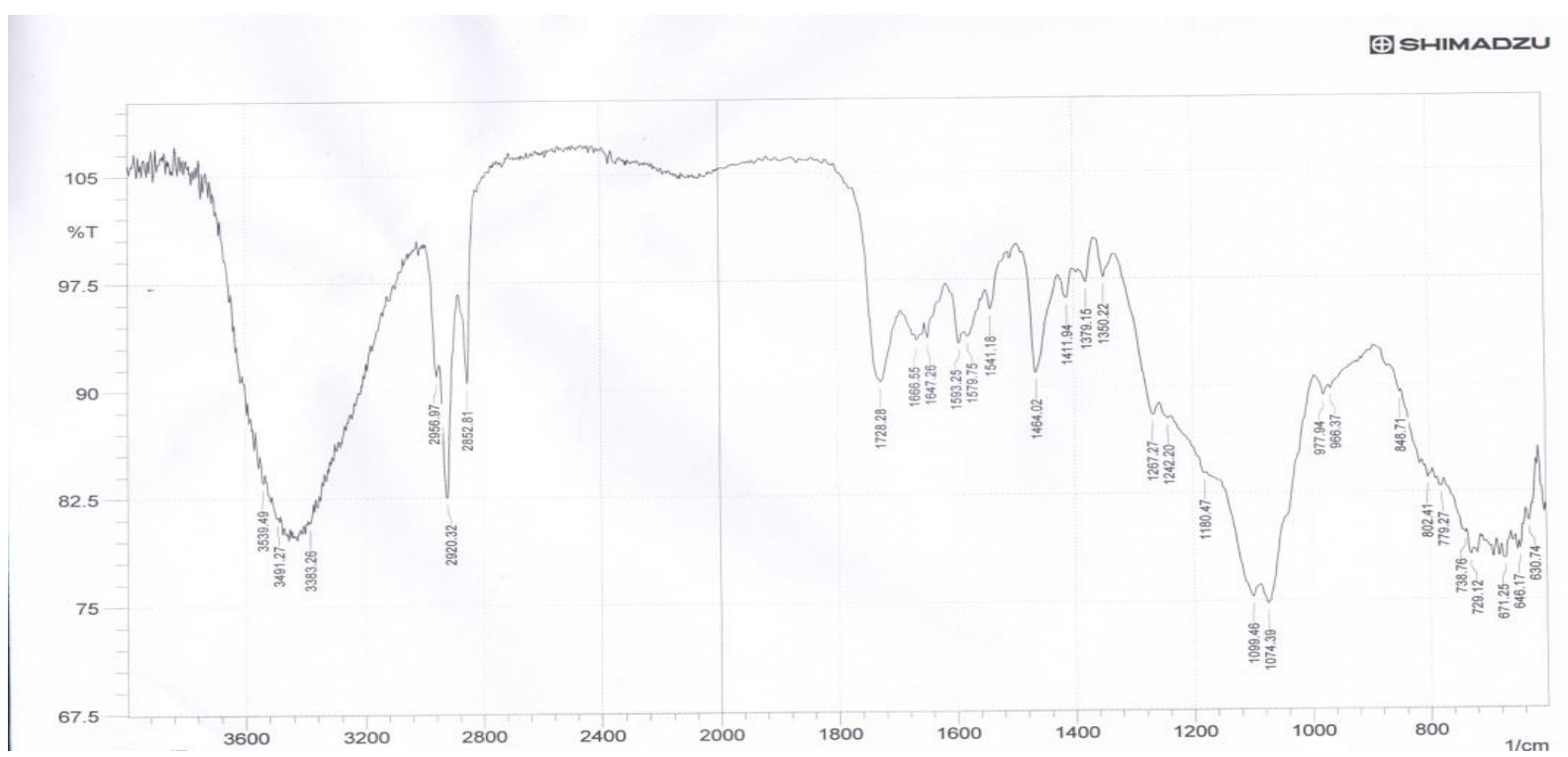

Figure 11. FTIR spectrum of isolated S compound

\section{Melting point}

- Isolated $\mathrm{R}$ compound melt at 171 to $175^{\circ} \mathrm{C}$ which match standard rosmarinic acid.

- Isolated CA compound melt at $221-224{ }^{\circ} \mathrm{C}$ which match standard caffeic acid.

- Isolated $\mathrm{G}$ compound melt at $298-300{ }^{\circ} \mathrm{C}$ which match standard genistein.

- Isolated S compound melt at $162-163^{\circ} \mathrm{C}$ which match standard silybin.

Isolation and purification of alkaloid from $\mathrm{FK}$ fraction by preparative layer chromatography

Preparative PLC was used to isolate and purify the compound that detected as alkaloid by spraying the developing plate by dragendorff reagent; methanol: water: formic acid $(25: 2: 73)$ was used as solvent system for developing the isolation.

Detection of isolated compound by thin layer chromatography (TLC)

This was performed to insure the purity of the isolated compound which identified by spraying the plate with dragendorff reagent and measuring the retardation factor $\left(R_{f}\right)$ after developing the TLC plate ; founding the $R_{f}$ value was $(0.193)$ by using methanol: water: formic $\operatorname{acid}(25: 2: 73)$ and was (0.654) by using methanol: water: formic acid (50:2:50) as solvent system. 


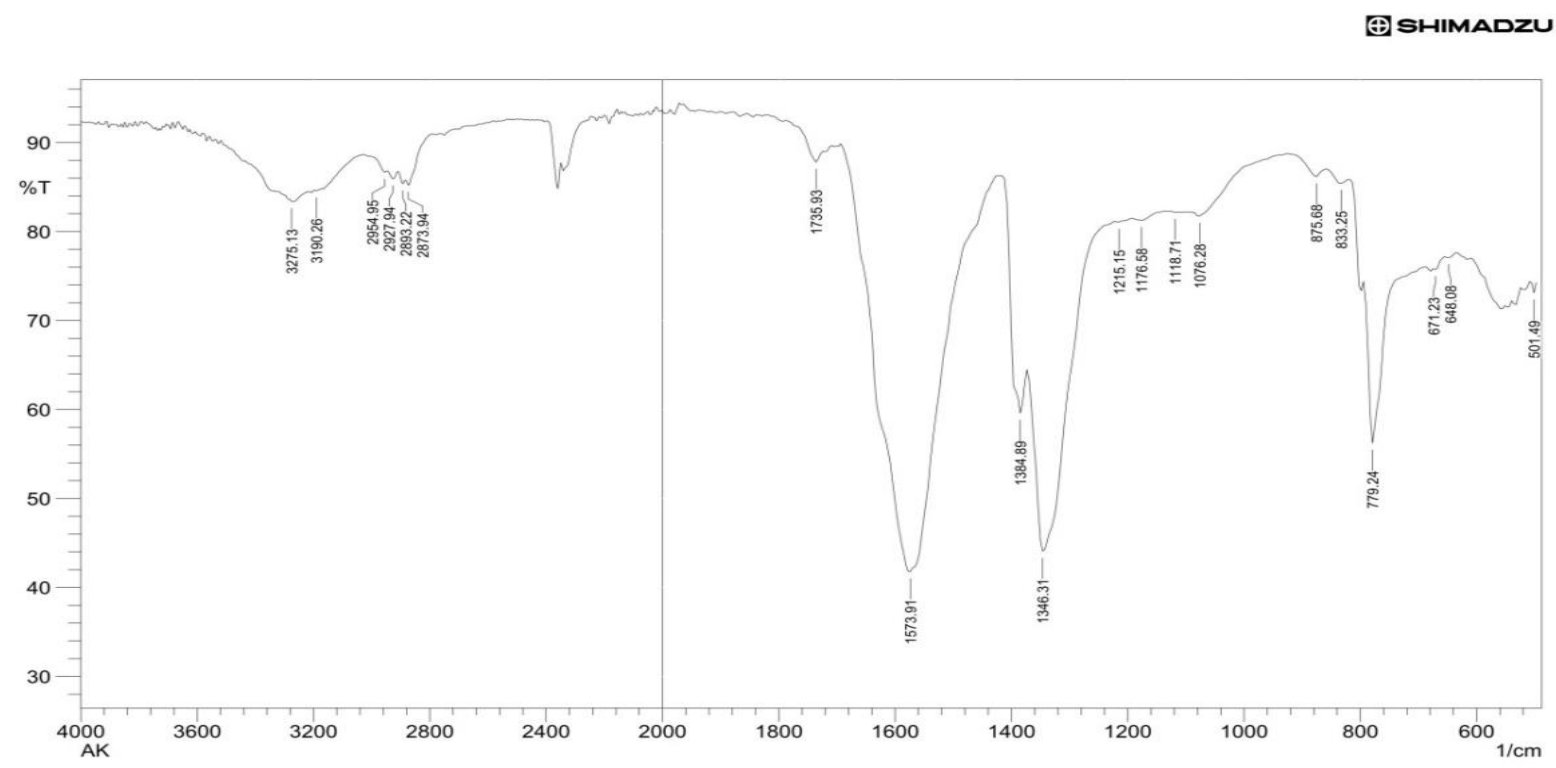

Figure 16. FTIR spectrum of isolated ak compound

\section{Discussion}

HPLC, IR analysis and melting point carried out in this study to identify and confirm the presence of rosmarinic acid, caffeic acid, genistein and silybin, and pyrolizidine alkaloid in the Iraqi Anchusa strigosa.

\section{Conclusion}

The results of this study exhibited the presence of phenols i.e., rosmarinic acid, caffeic acid and flavonoids, i.e., genistein, silybin in ethyl acetate fraction, pyrolizidine alkaloid after acid base extraction of crude plant material.

\section{Acknowledgments}

Financial provision and deeply grateful to the College of Pharmacy, University of Baghdad, for giving us the opportunity and facilities to accomplished this work.

\section{References}

1. Chakravarty hl. Plant wealth of iraq, vol. 1. Ministry of agriculture and agrarian reforms. Baghdad. 1976; 506.page 29.

2. Al-zubaidy am, tobakari sr. A comparative systematic study of the genus symphytum 1.(boraginaceae) with new first record of the species symphytum tuberosuml. From Iraq. Plant archives. 2018;18(2):2068-76

3. Al-douri na. A survey of medicinal plants and their traditional uses in Iraq. Pharmaceutical Biology. 2000 jan 1;38(1):74-9

4. Dresler s, szymczak g, wójcik m. Comparison of some secondary metabolite content in the seventeen species of the boraginaceae family.
Pharmaceutical Biology. 2017 jan 1;55(1):6915

5. Boskovic i, đukić da, maskovic p, mandić 1 , perovic s. Phytochemical composition and antimicrobial, antioxidant and cytotoxic activities of anchusa officinalis 1. Extracts. Biologia. 2018 nov 1;73(11):1035-41.

6. Ali al-rawi and h.l.chakravarty:medical plants of iraq.volume 15,1964 , page 13

7. Taban k, eruygur $\mathrm{n}$, üstün o. Biological activity studies on the aqueous methanol extract of anchusa talic e l. Subsp. Talic (ten.) Coutinho. Marmara Pharmaceutical Journal. 2018 sep $1 ; 22(3)$.

8. Said o, khalil $\mathrm{k}$,fuldes $\mathrm{s}$, azeizeh h.ethnopharmacological survey of medicinal plants in israel,the golan heights and the west bank region. J Ethnopharmacol 2002; 83:25165

9. Al-khalil s.asurvey of plants used in jurdinian traditional Pharmacogen1995;33:317-23

10. Jakovljević d, vasić s, stanković $m$, topuzović $\mathrm{m}$, čomić 1. The content of secondary metabolites and in vitro biological activity of anchusa officinalis 1.(boraginaceae) 2016.

11. Al-snafi ae. Therapeutic properties of medicinal plants: a review of plants with antioxidant activity (part 1). International Journal of Pharmacology and Toxicology. 2015;6(3):15982

12. Bacanli $m$, göktaş hg, başaran $n$, ari $n$, başaran aa. Beneficial effects of commonly used phytochemicals in diabetes mellitus. Acta Pharmaceutica Sciencia. 2016;54(1) 
13. Tsalkovich 1 , sallon $s$, paavilainen $h$, rosenmann h. Anti-alzheimer's disease related activities of israeli medicinal plants 2015

14. Al-salihi fg. Antimicrobial activity of volatile oil and fixed oil extracted from anchusa strigosa lab. Tikrit Journal Of Pure Science. 2009;14(2):21-4.

15. Torki a, khalaji-pirbalouty $\mathrm{v}$, lorigooini $\mathrm{z}$, rafieian-kopaei $\mathrm{m}$, sadeghimanesh a, rabiei $\mathrm{z}$. Anchusa talic extract: phytochemical and neuroprotective evaluation on global cerebral ischemia and reperfusion. Brazilian Journal of Pharmaceutical Sciences. 2018;54(1

16. Alallan 1, agha mi, omerein an, al balkhi mh. Anti-arthritic effects of anchusa strigosa extracts on complete freund's adjuvant-induced arthritis in rats. Journal of Pharmacognosy and Phytochemistry. 2018;7(6):679-85

17. Abbas $\mathrm{m}$, disi a, al-khalil $\mathrm{s}$. Isolation and identification of anti-ulcer components from anchusa strigosa root. Jordan Journal of Pharmaceutical Sciences 2009; 2(2):131-139

18. Siciliano $\mathrm{t}$, de leo $\mathrm{m}$, bader a, de tommasi $\mathrm{n}$, vrieling $\mathrm{k}$, braca a, morelli i. Pyrrolizidine alkaloids from anchusa strigosa and their antifeedant activity. Phytochemistry. 2005 jul 1;66(13):1593-600.

19. Al-khateeb eh, al-assi ga, shakya ak, al-rawi n, shalan n. Antioxidant potential of pistacia vera
1. Fruit hull, anchusa strigosa flowers and ilex paraguariensis a. St.-hil. Leaves extract. Oriental journal of chemistry. 2019 may $10 ; 35(3)$

20. Braca a, bader a, siciliano t, morelli $i$, de tommasi n. New pyrrolizidine alkaloids and glycosides from anchusa strigosa. Planta Medica. 2003 sep;69(09):835-41

21. Evans wc. Trease and evans' pharmacognosy. $16 \mathrm{TH}$ ed. Edinburgh london new york philadelphia st louis sydney toronto 2009: saunders 1td; 2009. $616 \mathrm{p}$

22. Waksmundzka-hajnos m., sherma j., kowalska t.:thin layer chromatography in phytochemistry (1STED.). Crc press. Usa: taylor\& Francis group 2008

23. Seal, t. Quantitative hplc analysis of phenolic acids, flavonoids and ascorbic acid in four different solvent extracts of two wild edible leaves, sonchus arvensis and oenanthe linearis of north-eastern region in india. Journal of Applied Pharmaceutical Science, . 2016. 6(2), 157-166

24. Ezghayer ma, kadhim ej. Uplc-esi-ms/ms and various chromatographic technique for identification of phytochemicals in populus euphratica oliv. Leaves extract. Iraqi Journal Of Pharmaceutical Sciences. 2020 Jun 24; 29 (1) :94 -114. 